\title{
Early and Long Term Outcomes of Corrective Operations for Tetralogy of Fallot: An Experience of Two Centers
}

\author{
Srikrishna Sirivella, Isaac Gielchinsky \\ Department of Cardiovascular \& Thoracic Surgery, Newark Beth Israel Medical Center, University of Medicine \\ \& Dentistry of New Jersey, Newark, New Jersey, USA \\ Email: sirivella@gmail.com
}

Received 24 August 2014; revised 24 September 2014; accepted 24 October 2014

Copyright (C) 2014 by authors and Scientific Research Publishing Inc.

This work is licensed under the Creative Commons Attribution International License (CC BY).

http://creativecommons.org/licenses/by/4.0/

(c) (i) Open Access

\section{Abstract}

Objectives: Pulmonary valve insufficiency and right ventricular dysfunction may contribute to early and late morbidity and mortality after repair of Tetralogy of Fallot. Right ventricular dysfunction may be attributed to ventriculotomy incision, especially, when it is combined with a transannular patch as employed in the transventricular repair. Transatrial/transpulmonary approach without ventriculotomy and an attempt to preserve the pulmonary valve has been advocated as a method potentially diminishing such adverse events. The prevalence of associated morbidity and mortality and analysis of the results of various surgical approaches for repair of Tetralogy of Fallot formed the basis of this study. Methods: Nine hundred and ninety five patients during 20 yearS period (from 1992 and 2012) with primary diagnosis of Tetralogy of Fallot that underwent total repair operations in two medical centers were analyzed. The mean age of the patients was $2.9 \pm 6.9 \mathrm{SE}$, with female/male ratio of 0.25 . The mean long follow-up was 94 months \pm 112 SD. Results: Repair via ventriculotomy with transannular patch was the most common technique $(n=627,63 \%)$, followed by infundibulotomy without transannular patch $(20 \%)$ and transatrial/transpulmonary approach without ventriculotomy (15\%). The operative and long term mortality were $3.2 \%$ and $4.4 \% ; 2 \%$ and $3.1 \% ; 2 \%$ and $2.7 \%$ respectively. The overall operative and long term mortality for repairs was $2.9 \%$ and $3.4 \%$, with high $3.94 \%$ and $6.6 \%$ respectively for repairs with right ventricular pulmonary valve conduit. There was statistically significant correlation between the type of repair and mortality risk. Use of transannular patch with ventriculotomy was associated with significant increase in overall mortality risk and operative mortality compared with ventriculotomy without transannular patch. [Odds ratio, 2.10; 95\% confidence interval: 1.29 - 3.64]. Operations that have been performed before 2000 have resulted in increased operative risk compared with those performed after 2000. [Odds ratio 1.45; 95\% confidence interval: 1.03 - 2.01]. Conclusions: Overall mortality for Tetralogy of Fallot repair was low. The repair by ventriculotomy with transannular patch was the most common technique and was associ- 
ated with higher mortality. Repairs through infundibulotomy without transannular patch and repair without ventriculotomy were less common, but were associated with lower mortality. Current advances in management, anatomical substrate of the lesion, choice of a repair and surgical expertise may all determine the mortality risk.

\title{
Keywords
}

\author{
Ttralogy of Fallot, Transventricular Repair, Transannular Patch, Ventriculotomy, \\ Transatrial/Transpulmonary Repair
}

\section{Introduction}

It has been well documented that the total and definitive surgical correction of Tetralogy of Fallot (TOF) generally carries low morbidity and mortality during the past few decades [1]-[5]. Nevertheless, there is increasing evidence of onset of late complications such as right ventricular dilatation and dysfunction, severe pulmonary insufficiency), ventricular arrhythmias and even sudden death. The rehospatalization rates due to ventricular dysfunction and the incidence of reoperation rates, mostly for pulmonary valve replacement, are reported to be as high as $30 \%$ during long term follow-up [6]-[10].

The early surgical mortality and morbidity and increase in late adverse outcomes are attributed to deterioration of right ventricular function when a generous ventriculotomy is utilized in conventional transventricular repair technique, especially if combined with a transannular patch. The latter results in significant pulmonary valve insufficiency in [11]-[15].

The, transatrial/transpulmonary (TA/TP) repair, that was popularized in the 1980s and 1990s [7]-[12], does not utilize ventriculotomy involving the body of the RV, but only a minimal, if any, extension of a pulmonary arteriotomy across the pulmonary valve annulus or creation of a separate and minimal infundibulotomy incision for transection of the hypertorophied muscular bands without transecting the pulmonary valve annulus. These techniques are less damaging to the right ventricle and the preservation of pulmonary valve competency is claimed to be associated with an improved early and late outcomes [14]-[21]. Surgical techniques employed for repair of tetralogy differ widely among institutions [3]-[6] [20] [21], and the prevalence and outcomes of these different techniques, therefore vary. A prospective randomized study of various techniques employed in repair of Tetralogy of Fallot may clarify the choice of an optimal technique and the timing of repair.

\section{Materials and Methods}

The operations performed for total correction of Tetralogy of Fallot in two medical centers (Newark Beth Israel Medical Center, Newark, New Jersey and SVIMS, Tirupati) during a 20 year period (from 1992 to 2012) were retrospectively reviewed. Included in this study were 995 patients who had undergone corrective procedures. This study excluded patients who were referred to other centers and surgical procedures including palliative operations that were performed for TOF. The palliative procedures included systemic pulmonary artery shunts such as modified and classic Blalock-Taussig shunts, infundibulotomy, pulmonary valvotomy and/or arteriotomy. The age ranged from 1 year to 22 years (mean age in years $2.9+6.9 \mathrm{SD}$ ) and the male female ratio was 4:1 (796/199). The corrective procedures performed for TOF were: 1) Ventriculotomy, enlargement of the pulmonary valve annulus with tranannular patch; 2) Ventriculotomy or infundibulotomy without transannular patch; 3) Repair with right atriotomy and pulmonary arteriotomy without ventriculotomy or transannular patch; 4) Ventriculotomy with right ventricle to pulmonary artery valve conduit. All the repairs included closure of an associated atrial septal defect through the right atriotomy, closure of ventricular septal defect through ventriculotomy or right atriotomy. In majority of the of the patients pulmonary valve annulus was sized with Baker's dilators and a $\mathrm{z}$ value of -1.5 to 0 was considered an adequate size. In most of the patients a goal was also set to achieve right ventricle/left ventricle $(\mathrm{RV} / \mathrm{LV})$ pressure ratio of $<0.75$ post repair. The data on pulmonary valve annular sizes, sizes of branch pulmonary arteries at lung hilum and RV/LV pressure ratios post repair were not available for detailed analysis. 


\subsection{Surgical Technique}

All operations were performed on cardiopulmonary bypass with bicaval venous cannulation for venous drainage and ascending aortic cannulation for arterial return. The surgeries were performed under moderate hypothermia $\left(27^{\circ} \mathrm{C}\right.$ to $\left.28^{\circ} \mathrm{C}\right)$ and cold blood cardioplegic arrest. In patients with associated secundum atrial septal defect (ASD) initial atriotomy was made to close the defect and to resect the obstructive muscular bands of the right ventricular outflow tract. The ventricular septal defect was then closed. The pulmonary arteriotomy was then made to size the annulus and do pulmonary valvotomy or resect dysplastic pulmonary valve. If pulmonary annulus was inadequate the annulus was transected and the incision was extended to the infundibulum (ventriculotomy) and closed with a transannular patch. If pulmonary annulus was adequate, the arteriotomy was closed primarily or with a patch if necessary.

In patients without an ASD, initially a pulmonary arteriotomy was made to evaluate the size of PA annulus and if the size was inadequate the annulus was transected and the incision was extended to the infundibulum (ventriculotomy). All obstructive muscular bands were excised, followed by a closure of the ventricular septal defect. The incision was closed with adequate transannular patch. If the pulmonary annulus size was adequate only a pulmonary valvotomy was done, the resection of the obstructive muscle bands and closure of the ventricular septal defect (VSD) was done through right atriotomy. If resection of the bands and or closure of the VSD were not technically feasible or inadequate an infundibulotomy incision was made to complete the procedure.

If the infundibular stenosis was moderately severe or severe initial ventriculotomy incision was made to resect all obstructive muscular bands and the VSD was then closed. If the size of the pulmonary annulus was inadequate, the annulus was transected and a transannular patch was placed. Associated ASD was closed through right atriotomy.

If pulmonary valve is severely dysplastic or stenotic or associated with pulmonary atresia at initial operation and in recurrent pulmonary valve stenosis or pulmonary insufficiency, if the size of the pulmonary arteries were adequate (based on $\mathrm{z}$ values for the body size) a right ventricle to pulmonary artery valve conduit (RV-PA) was placed.

The above corrective operations performed for TOF were analyzed in regard to the operative mortality, long term mortality and survivals and other variable such as age, prior palliative surgery. The operative mortality was defined as a death occurring within 30 days after surgery in or out of the hospital or a death occurred after 30 days during the same hospitalization subsequent to the operation. The long term mortality was defined as a death occurring in and out of the hospital on a later follow-up [22]. The follow-up ranged from 6 months to 180 months with a mean follow-up of 94 months \pm 112 SD.

\subsection{Statistical Analysis}

Statistical data were analyzed with SPSS for Windows, release 10.0 (SPSS Inc., Chicago, IL, USA). Incidence and patient numbers are expressed as absolute numbers and percentages for categorical variables (e.g. year of surgery). The mean values and standard deviations (SDs) were used to describe numerical variables (e.g. age). Operative mortality and long term mortality is reported as a percentage. Patient's procedure mortality was compared with the rest of the group with t-test and $\chi^{2}$ test where appropriate. Analysis of variance (ANOVA) and $\chi^{2}$ tests were used for comparing the results of three repair techniques. The multivariate logistic regression analysis was implemented to identify potential risk factors for mortality and calculated the odds ratios (OR) and 95\% confidence intervals (CI).

\section{Results}

A total of 995 corrective surgical procedures for TOF performed in two medical centers were analyzed. Overall, repair via ventriculotomy with transannular patch was the most prevalent technique $(n=627,63 \%)$. Repair via ventriculotomy without transannular patch was performed in 193 (19.3\%) patients. Repair without ventriculotomy was performed in 145 patients (14.5\%) and repair with RV-PA conduit in 30 patients (3\%). The list of morbid complications encountered in this group either at initial hospital stay or on follow up is shown in Table 1.

The clinical characteristics of patients who underwent either of three repair procedures transatrial/transpulmonary repair, ventriculotomy without transannular patch and ventriculotomy with transannular patch are shown in Table 2. 
Table 1. List of morbid complications in 995 TOF corrective operations.

\begin{tabular}{cc}
\hline Right ventricular dysfunction with pulmonary valve insufficiency \\
\hline Right ventricular dysfunction without pulmonary valve insufficiency \\
\hline Deep sternal wound infection & Postoperative bleeding \\
Permanent heart block & Pleural effusion \\
Prolonged ventilatory support & Respiratory failure \\
Ventricular tachyarrhythmias & Atrial tachyarrhythmias \\
Bacterial/ fungal sepsis & Multiorgan failure \\
\hline
\end{tabular}

TOF $=$ Tetralogy of Fallot.

Table 2. Patient characteristics in different repair operations for TOF.

\begin{tabular}{|c|c|c|c|c|c|c|c|}
\hline & \multicolumn{2}{|c|}{ Inf/ TAP } & \multicolumn{2}{|c|}{ Inf/ No-TAP } & \multicolumn{2}{|c|}{ TA/TP No-Inf } & \multirow[t]{2}{*}{ P value } \\
\hline & $\mathbf{n}$ & $\%$ & $\mathbf{n}$ & $\%$ & $\mathbf{n}$ & $\%$ & \\
\hline $\begin{array}{l}\text { Age (months) } \\
\text { (Mean } \pm \text { SE) }\end{array}$ & \multicolumn{2}{|c|}{$27.4 \pm 39.8$} & \multicolumn{2}{|c|}{$54.4 \pm 68.2$} & \multicolumn{2}{|c|}{$30.7 \pm 63.7$} & $<0.001$ \\
\hline \multicolumn{8}{|l|}{ Year of surgery } \\
\hline $1992-2000$ & 201 & 32 & 60 & 31 & 54 & 37.3 & \multirow{3}{*}{$<0.0001$} \\
\hline$(n=315)$ & & & & & & & \\
\hline $\begin{array}{c}2001-2012 \\
(n=650)\end{array}$ & 426 & 68 & 133 & 69 & 91 & 62.7 & \\
\hline \multicolumn{8}{|c|}{ Previous palliative surgery } \\
\hline Yes & 12 & 1.9 & 3 & 1.6 & 2 & 1.4 & \multirow[t]{2}{*}{0.052} \\
\hline No & 615 & 98.1 & 190 & 98.4 & 143 & 98.6 & \\
\hline
\end{tabular}

Inf = infundibulotomy (ventriculotomy); $\mathrm{n}=$ number of patients (repairs); $\pm \mathrm{SE}=$ standard error; $\mathrm{TAP}=$ transannular patch; TA/TP = transatrial/transpulmonary (repair); \% = percentage; TOF = Tetralogy of Fallot.

The characteristics included age at operation, history of previous palliative surgery and the year of operations (i.e.: from 1992 to 2000 vs. 2001 to 2012). The three groups differ significantly in age (by ANOVA). Patients operated by infundibulotomy without transannular patch were older (age in months, mean $54.4 \pm 68.2 \mathrm{SD}$ ) than patients that have been treated with the other two operations mean $27.4 \pm 39.8$ SD for infundibulotomy with transannular patch and mean $30.7 \pm 63.7 \mathrm{SD}$ for transatrial/transpulmonary repair.

The three groups collectively differ also in the incidence of procedures with regard to the year of operation. After 2000 most of the operations for TOF involved all three total repair procedures (>65\%) but prior to 2000 only $30 \%$ of total repair procedures were done. The remaining TOF patients not treated by total corrective operations were treated with palliative shunts, pulmonary valvotomy, infundibulotomy or referred to other centers. The incidence of prior palliative surgery was slightly more in patients treated by infundibulotomy and transannular patch $(\mathrm{P}=0.052)$.

The operative mortality for transpulmonary/transatrial repair technique without ventriculotomy was only $2 \%$ with a long term mortality of $2.7 \%$, but it was $3.2 \%$ and $4.4 \%$ respectively for a ventriculotomy incision with a transannular patch. The cumulative operative mortality for all corrective repairs (in 965 patents) was $2.9 \%$, but it was slightly higher 3.3\% for a repair with RV-PA valve conduit. The overall operative mortality of all corrective procedures performed for TOF was only $2.8 \%$ with a long term mortality of $4.02 \%$ on a long follow-up. Table 3 depicts the number and frequency of each of the types of surgical repair for TOF and the corresponding operative mortality and long term mortality.

Analyzing the operative and long-term mortality for different repair techniques (see Table 4) the results indicate that no statistically significant differences were observed in the age distribution of the patient, performance of previous palliative surgery, and the year of surgery, though slightly increased short term and long term mortality rates were observed for years before 2000 (2.88\%) compared with those performed after 2000 (2.06\%). Though previous palliative surgery had survival advantage over no prior palliation on repair procedures the results did not assume statistical significance ( $\mathrm{P}=0.5$ and 0.53 ). The operative mortality and a long term mortality for repairs without previous palliative surgery were $2.9 \%$ and $3.9 \%$ vs $0 \%$ mortality for repairs with prior palliative 
Table 3. Operative mortality and long term mortality for total correction of TOF.

\begin{tabular}{|cccccccc}
\hline Operative procedure & \multicolumn{2}{c}{ Operations } & \multicolumn{2}{c}{ Operative mortality } & \multicolumn{3}{c}{ Long term mortality } \\
\hline 1) Transatrial/transpulmonary repair no ventriculotomy & $\mathbf{n}$ & $\mathbf{\%}$ & $\mathbf{n}$ & $\mathbf{\%}$ & $\mathbf{n}$ & $\%$ \\
2) Infundibulotomy no transannular patch & 145 & 14.5 & 3 & 2 & 4 & 2.7 \\
3) Ventriculotomy with transannular patch & 193 & 19.3 & 4 & 2 & 6 & 3.1 \\
Total repairs & 627 & 63 & 20 & 3.2 & 28 & 4.4 & 3.94 \\
4) Repair with RV-PA valve conduit & 965 & & 28 & 2.9 & 38 & 6.6 \\
Total procedures (n) & 30 & 3 & 1 & 3.3 & 2 & 40 & 4.02 \\
\hline
\end{tabular}

$\mathrm{n}$ = number of operations; RV-PA = right ventricle to pulmonary artery; TOF = Tetralogy of Fallot; \% = percentage.

Table 4. Analysis of operative and long term mortality of TOF repairs in 965 patients.

\begin{tabular}{|c|c|c|c|c|c|}
\hline & \multicolumn{2}{|c|}{ Operative mortality (n = 28) } & \multicolumn{2}{|c|}{30 days survivals $(n=937)$} & \multirow[t]{2}{*}{ P value } \\
\hline & $\mathbf{n}$ & $\%$ & $\mathbf{n}$ & $\%$ & \\
\hline Age (years, mean $\pm \mathrm{SD}$ ) & \multicolumn{2}{|c|}{$2.6 \pm 5.2$} & \multicolumn{2}{|c|}{$2.1 \pm 4.8$} & 0.62 \\
\hline \multicolumn{6}{|l|}{ Year of surgery } \\
\hline $1992-2000$ & 10 & 3.2 & 305 & 96.8 & 0.052 \\
\hline 2001-2012 & 18 & 2.8 & 632 & 97 & \\
\hline \multicolumn{6}{|l|}{ Prior palliative surgery } \\
\hline NO & 28 & 2.9 & 920 & 97.2 & 0.5 \\
\hline \multirow[t]{3}{*}{ YES } & 0 & 0 & 17 & 100 & \\
\hline & \multicolumn{2}{|c|}{ Long term mortality $(n=38)$} & \multicolumn{2}{|c|}{ Long term survivals $(n=927)$} & $P$ value \\
\hline & $\mathbf{n}$ & $\%$ & $\mathbf{n}$ & $\%$ & \\
\hline \multicolumn{6}{|l|}{ Year of surgery } \\
\hline $1992-2000$ & 13 & 4 & 302 & 96 & 0.06 \\
\hline $2001-2012$ & 25 & 3.8 & 625 & 96 & \\
\hline \multicolumn{6}{|l|}{ Prior palliative surgery } \\
\hline NO & 38 & 3.9 & 910 & 96 & 0.053 \\
\hline YES & 0 & 0 & 17 & 100 & \\
\hline Age (years, mean \pm SD) & \multicolumn{2}{|c|}{$2.4 \pm 5.3$} & \multicolumn{2}{|c|}{$2.3 \pm 4.9$} & 0.8 \\
\hline
\end{tabular}

$\mathrm{N}=$ number of patients; $\pm \mathrm{SD}$ = standard deviation; TOF = Tetralogy of Fallot.

surgery.

The results of logistic regression analysis showed significant association between operative mortality risk and the type of surgical repair. Ventriculotomy with transannular patch was associated with significantly increased mortality risk compared with repair without ventriculotomy [OR, 2.10; 95\% CI: 1.29 - 3.64]. If a year of surgery, patient's age and history of prior palliative surgery were analyzed there was no significant change in OR for ventriculotomy with or without transannular patch. For operation with ventriculotomy but without transannular patch the mortality risk was 1.06 times more than operation without ventriculotomy (95\% CI: 0.57 - 2.12), but it did not assume statistical significance. On multivariate analysis there was a significant risk of both operative and long term mortality for the year of surgery: there is statistically significant evidence that patients operated before 2000 have increased mortality risk compared with those operated from year 2000 onwards (OR, 1.45, 95\% CI: 1.03 - 2.013) for operative mortality, and (OR, 1.42, 95\% CI: 1.02 - 1.96) for long term mortality.

\section{Discussion}

Due to advances in surgical technique, anesthesia and perioperative management, many centers reported very good early outcomes for the surgical repair of Tetralogy of Fallot [1]-[5] [15]-[17]. Notwithstanding these results, there is continued interest to ward off or reduce the incidence of late complications subsequent to repair such as right ventricular dysfunction and dilatation, pulmonary valve insufficiency, ventricular arrhythmias and sudden death [6]-[10]. Many studies support total correction of lesion in neonates and young infants, in whom ventricu- 
lotomy and trans-annular patch is used routinely. Early total repair may be associated with late complications such as ventricular dilatation and pulmonary valve insufficiency which may lead to increased reoperation rates for pulmonary valve replacement. Implantation of various monocusp valves such as allograft, pericardial, or GoreTex at initial repair to minimize pulmonary insufficiency were attempted (pericardial, allograft or polytetrafluoroethylene), but the long-term outcomes of these procedures are not known. Most studies therefore, focused on developing strategies to minimize the late complications and prefer to avoid total correction in neonates and young infants.

Transatrial and transpulmonary repair without infundibulotomy may allow maximal preservation of the RV and pulmonary valve and this technique may be employed even in neonates for total repair [11]-[13]. The advocates of this technique suggest that the incidence of late RV dysfunction arrhythmias and reoperation for pulmonary valve replacement may be reduced [12] [13] [15] [18] [19] Avoiding infundibulotomy during repair may not allow adequate resection of hypertrophic muscular bands to relieve right ventricular outflow obstruction which may be associated with poor early outcomes due to persistent outflow tract obstruction. In the presence of existing controversies dilemma persisted for a choice of an optimal repair technique by a surgeon and the present data reflecting the both early and long term outcomes of different techniques for total repair are sparse [21].

This study demonstrated that overall short term and long term mortality for total correction of TOF was low (2.2\% and $4.02 \%)$ and the mortality for repairs was much lower than the repairs with valve conduit subgroup (2.8\% and $3.94 \%$ vs. $3.2 \%$ and $6.6 \%$ ) Repairs with ventriculotomy with or without transannular patch account more than three quarters (85\%) of all repair procedures, and ventriculotomy with transannular patch was associated with higher mortality (3.2\% and $4.4 \%$ ) than the other repair techniques. Despite concerns of ventricular dysfunction and other long-term adverse effects of a ventriculotomy incision, transatrial/transpulmonary repair without ventriculotomy was less prevalent, but was associated with lowest mortality ( $2 \%$ and $2.7 \%$ ). These results differ from data published from the Society of Thoracic Surgeons Database, which showed an overall discharge mortality of $1.3 \%$ for primary TOF repair, and $0.9 \%$ for repair following earlier palliation [21]. These results may suggest that differences in mortalities associated with different types of repair may be attributed to anatomical substrate, surgical expertise, clinical practice and referral pattern of the patient population prevailed in these institutions.

There were also lack of statistically significant differences on preoperative patient characteristics, such as year of surgery or history of prior palliative surgery, between the three main types of reparative procedures, though patients who had undergone repair by ventriculotomy—non-TAP were significantly older. The anatomical substrate of the lesion may also be an important determinant of mortality, since patients who had undergone repair by ventriculotomy — non-TAP were slightly older and may represent more favorable anatomical substrate with lower mortality than ventriculotomy - with TAP, a repair technique that was commonly employed in infants and neonates. Similarly, the TA-TP repair group, which was less prevalent, had much lower mortality possibly because it includes anatomically and pathophysiologically more favorable surgical substrates. These results however, cannot be corroborated in the absence of detailed analysis of the size of pulmonary annulus, pulmonary artery branch sizes and post repair RV/LV pressure ratios.

Despite the differences in early and late outcomes observed for the different surgical options investigated for total repair of TOF, recommendation of a specific surgical repair technique over the other is not justified. The transatrial and transpulmonary repair without ventriculotomy may be a surgical option of the future for selected anatomical substrates of TOF due to improved outcomes noticed as compared to other techniques. However, the mortality differences observed in this study were not primarily attributed to the surgical approaches employed, but other factors such as the age, a year of surgery and the anatomical substrate of the lesion could have influenced the final outcomes. The optimal repair technique would be therefore, dictated by not only the anatomical substrate of the lesion, but the patient's age, prevailing surgical practice and other patient preoperative characteristics which all should be taken into relevance in an effort to improve patient outcomes.

\section{References}

[1] Castaneda, A.R., Freed, M.D., Williams, R.G. and Norwood, W.I. (1977) Repair of Tetralogy of Fallot in Infancy. Early and Late Results. Journal of Thoracic and Cardiovascular Surgery, 74, 372-381.

[2] Kirklin, J.W., Ellis Jr., F.H., McGoon, D.C., DuShane, J.W. and Swan, H.F.C. (1959) Surgical Treatment for the Tetralogy of Fallot by Open Intracardiac Repair. Journal of Thoracic Surgery, 3, 22-51.

[3] Reddy, V.M., Liddicoat, J.R., McElhinney, D.B., Brook, M.M., Stanger, P. and Hanley, F.L. (1995) Routine Primary 
Repair of Tetralogy of Fallot in Neonates and Infants Less Than Three Months of Age. Annals of Thoracic Surgery, 60, S592-596.

[4] Pigula, F.A., Khalil, P.A., Mayer, J.E., del Nido, P.J. and Jonas, R.A. (1999) Repair of Tetralogy of Fallot in Neonates and Young Infants. Circulation, 100, 157-161. http://dx.doi.org/10.1016/0003-4975(95)00732-6

[5] Hirsch, J.C., Mosca, R.S. and Bove, E.L. (2000) Complete Repair of Tetralogy of Fallot in the Neonate: Results in the Modern Era. Annals of Surgery, 232, 508-514. http://dx.doi.org/10.1097/00000658-200010000-00006

[6] Fuster, V., McGoon, D.C., Kennedy, M.A., Rotter, D.G. and Kirklin, J.W. (1980) Long-Term Evaluation (12 to 22 Years) of Open Heart Surgery for Tetralogy of Fallot. American Journal of Cardiology, 46, 635-642. http://dx.doi.org/10.1016/0002-9149(80)90514-7

[7] Hickey, E.J., Veldman, G., Bradley, T.J., Aungkana, G., Manlhiot, C., Williams, W.G., et al. (2009) Late Risk of Outcomes for Adults with Repaired Tetralogy of Fallot from an Inception Cohort Spanning Four Decades. European Journal of Cardiothoracic Surgery, 35, 156-164. http://dx.doi.org/10.1016/j.ejcts.2008.06.050

[8] d’Udekem, Y., Ovaert, C., Grandjean, F., Gerin, V., Cailteux, M., Shango-Lody, P., et al. (2000) Tetralogy of Fallot: Transannular and Right Ventricular Patching Equally Affect Late Functional Status. Circulation, 102, 116-122.

[9] Bacha, E.A., Scheule, A.M., Zurakowski, D., Erickson, L.C., Judy Hung, J., Lang, P., et al. (2001) Long-Term Results after Early Primary Repair of Tetralogy of Fallot. Journal of Thoracic and Cardiovascular Surgery, 122, $154-161$. http://dx.doi.org/10.1067/mtc.2001.115156

[10] Lindberg, H.L., Saatvedt, K., Seem, E., Hoel, T. and Birkeland, S. (2011) Single-Center 50 Years’ Experience with Surgical Management of Tetralogy of Fallot. European Journal of Cardiothoracic Surgery, 40, 538-542.

[11] Hudspeth, A.S., Cordall, A.R. and Johnston, F.R. (1963) Transatrial Approach to Total Correction of Tetralogy of Fallot. Circulation, 27, 796-800. http://dx.doi.org/10.1161/01.CIR.27.4.796

[12] Kawashima, Y., Kitamura, S., Nakano, S. and Yagihara, T. (1981) Corrective Surgery for Tetralogy of Fallot without or with Minimal Right Ventriculotomy and with Repair of the Pulmonary Valve. Circulation, 64, 147-153.

[13] Karl, T.R., Sano, S., Pornviliwan, S. and Mee, R.B. (1992) Tetralogy of Fallot: Favorable Outcome of Nonneonatal Transatrial, Transpulmonary Repair. Annals of Thoracic Surgery, 54, 903-907. http://dx.doi.org/10.1016/0003-4975(92)90646-L

[14] Fraser Jr., C.D., McKenzie, E.D. and Cooley, D.A. (2001) Tetralogy of Fallot: Surgical Management Individualized to the Patient. Annals of Thoracic Surgery, 71, 1556-1561. http://dx.doi.org/10.1016/S0003-4975(01)02475-4

[15] Giannopoulos, N.M., Chatzis, A.K., Karros, P., Zavaropoulos, P., Papagiannis, J., Rammos, S., et al. (2002) Early Results after Transatrial/Transpulmonary Repair of Tetralogy of Fallot. European Journal of Cardiothoracic Surgery, 22, 582-586. http://dx.doi.org/10.1016/S1010-7940(02)00403-7

[16] Pacifico, A.D., Sand, M.E., Bargeron, L.M. and Calvin, E.C. (1987) Transatrial Transpulmonary Repair of Tetralogy of Fallot. Journal of Thoracic and Cardiovascular Surgery, 93, 919-924.

[17] Stellin, G., Milanesi, O., Rubino, M., Michielon, G., Moreolo, G.S., Boneva, R., et al. (1995) Repair of Tetralogy of Fallot in the First Six Months of Life: Transatrial versus Transventricular Approach. Annals of Thoracic Surgery, 60, 588-591.

[18] Kanter, K.R., Kogon, B.E., Kirshbom, P.M. and Carlock, P.R. (2010) Symptomatic Neonatal Tetralogy of Fallot: Repair or Shunt? Annals of Thoracic Surgery, 89, 858-863. http://dx.doi.org/10.1016/j.athoracsur.2009.12.060

[19] Sfyridis, P.G., Kirvassilis, G.V., Papagiannis, J.K., Avramidis, D.P., Ieromonacho, C.G., Zavaropoulos, P., et al. (2013) Preservation of Right Ventricular Structure and Function Following Transatrial-Transpulmonary Repair of Tetralogy of Fallot. European Journal of Cardiothoracic Surgery, 43, 336-342. http://dx.doi.org/10.1093/ejcts/ezs221

[20] Boni, L., Garcia, E., Galletti, L., Perez, A., Herrera, D., Ramos, V., et al. (2009) Current Strategies in Tetralogy of Fallot Repair: Pulmonary Valve Sparing and Evolution of Right Ventricle/Left Ventricle Pressures Ratio. European Journal of Cardiothoracic Surgery, 35, 885-890. http://dx.doi.org/10.1016/j.ejcts.2009.01.016

[21] Al Habib, H.F., Jacobs, J.P., Mavroudis, C., Tchervenkov, C.I., O’Brien, S.M., Mohammadi, S., et al. (2010) Contemporary Patterns of Management of Tetralogy of Fallot: Data from the Society of Thoracic Surgeons Database. Annals of Thoracic Surgery, 90, 813-820. http://dx.doi.org/10.1016/j.athoracsur.2010.03.110

[22] Jacobs, J.P., Mavroudis, C., Jacobs, M.L., Maruszewski, B., Tchervenkov, C.I., Lacour-Gayet, F.G., et al. (1999) What Is Operative Mortality? Defining Death in a Surgical Registry Database: A Report of the STS Congenital Database Taskforce and the Joint EACTS-STS Congenital Database Committee. Annals of Thoracic Surgery, 81, 1937-1941. http://dx.doi.org/10.1016/j.athoracsur.2005.11.063 
Scientific Research Publishing (SCIRP) is one of the largest Open Access journal publishers. It is currently publishing more than 200 open access, online, peer-reviewed journals covering a wide range of academic disciplines. SCIRP serves the worldwide academic communities and contributes to the progress and application of science with its publication.

Other selected journals from SCIRP are listed as below. Submit your manuscript to us via either submit@scirp.org or Online Submission Portal.
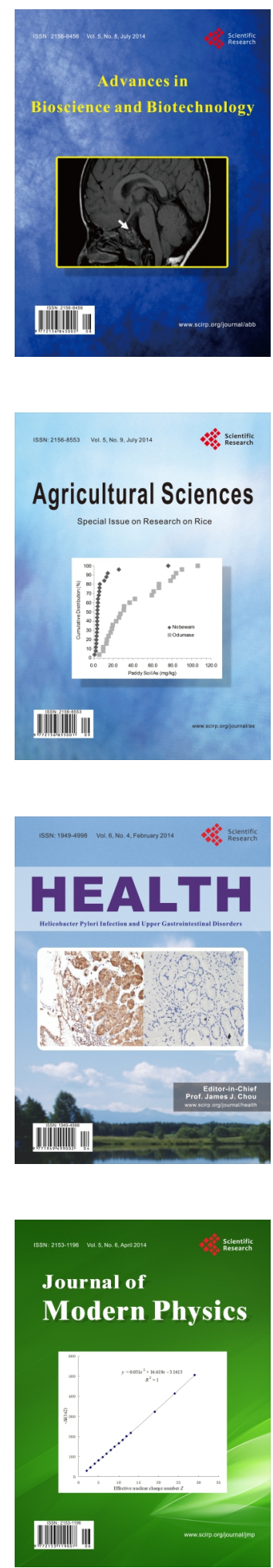
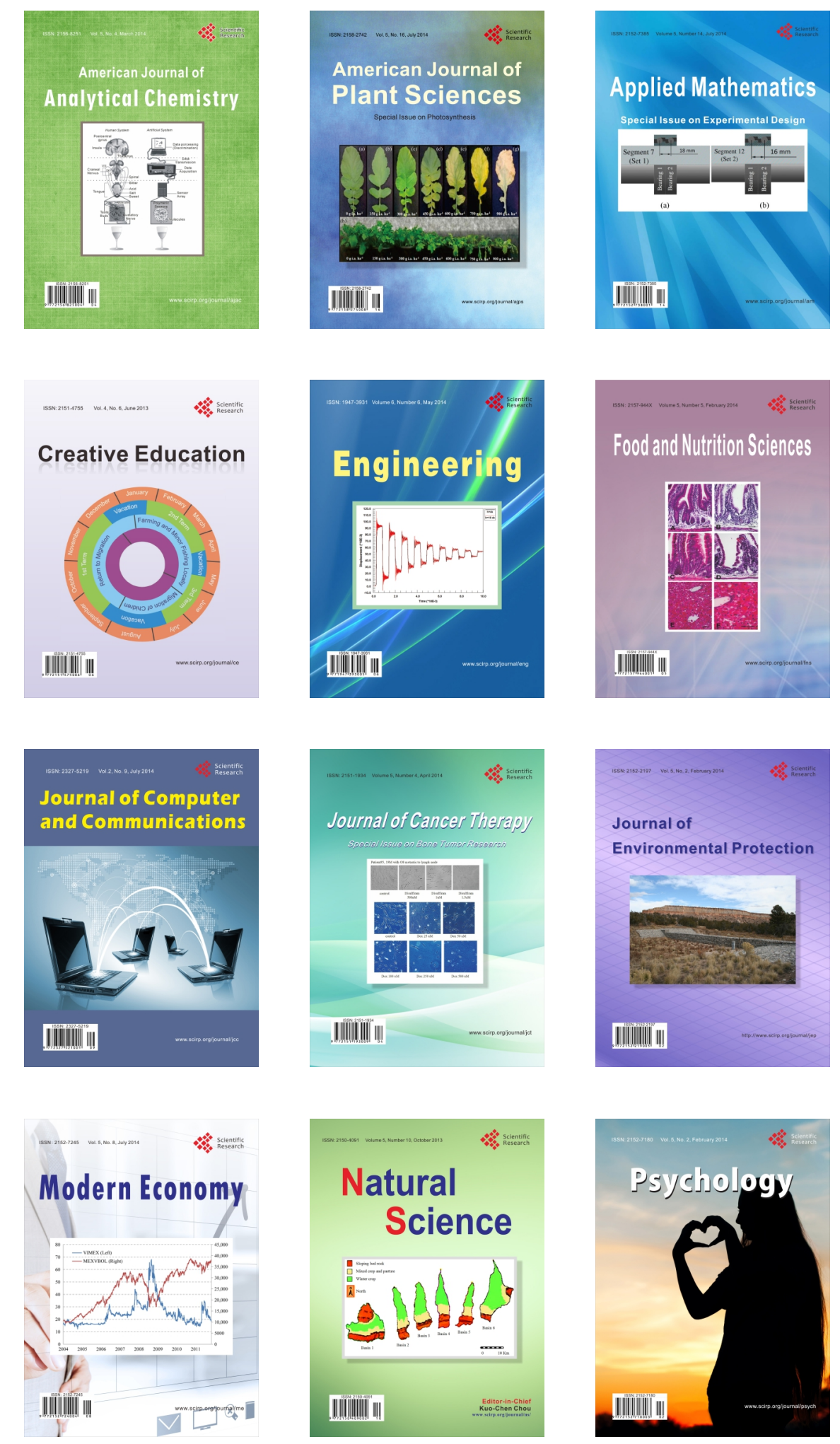